Ma-s

Scott, Wililiam B.

A COLLECTION OF FOSSIL MAMMALS FROM THE COAST OF ZULULAND. 


\section{HARVARD UNIVERSITY.}

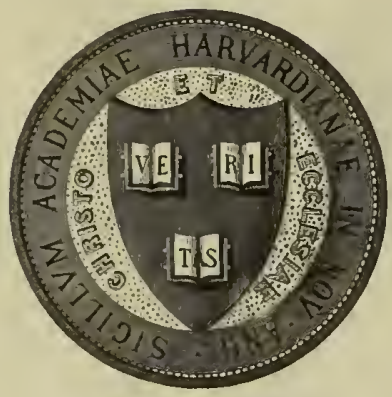

\section{LIBRARY}

OF THE

MUSEUM OF COMPARATIVE ZOÖLOGY 59.092

GIFT OF

Harvoud college library Cpril 17. 1922 
59,092

[Reprinted from the Third Report of the Geological Survey of Natal and Zululand, published May, 1907.]

A COLLECTION OF FOSSIL MMMNALS

FROM

THE COAST OF ZULULAND.

By WILLIAM B. SCOTT,

Princeton University, U.S.A.

c, 



\title{
A COLLECTION OF FOSSIL MAMMALS FROM \\ THE COAST OF ZULULAND.
}

\author{
By WILLIAM B. SCOTT,
}

Princeton Unizersity, U.S.A. 


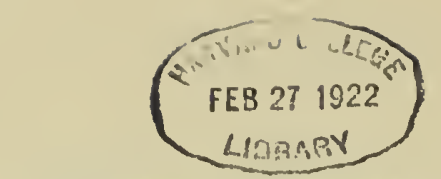

Princeton Uniperaitg Iibrs.ry

TRAMBFERRED TO

MUSEUH OF CCMPARATIVE ZOOLOGY 


\title{
A COLLECTION OF FOSSIL MAMMALS FROM THE COAST OF ZULULAND.
}

BY

\author{
WILLIAM B. SCOTT,
}

Princeton Universily, U.S.A.

Hitherto almost no remains of Tertiary mammals have been reported from South Africa, and therefore unusual interest attaches to a small collection of such remains gathered by Mr. Anderson on the coast of Zululand, and by him sent to the writer for determination.

Concerning the position and mode of occurrence of these fossils Mr. Anderson writes as follows: "The fossils were scattered over a" "large flat outcrop of shales, which occurs below the level of ordinary" "low-water mark, and is only exposed under the exceptional circum-" "stances of a strong south-easterly gale and a neap tide, when the" "large covering of sand is removed. Overlying this bed are a series" "of shales with a few scattered bones and crustacean and fish" "remains. Above these a thin layer containing Foraminifera, and" "then a foot or so containing marine Mollusca, which Mr. Etheridge" "referred to the Tertiary period; above this a thick series (probably" " over 100 feet) of false bedded sands of various colours covered by" " the Recent sand dunes."

Though described as a shale in the foregoing account, the matrix still adhering to the bones appears rather to be a friable, unconsolidated, and somewhat granular mud, containing little clay and a very large quantity of fine sand, coloured dark brown by vegetable matter.

The teeth appear to have been very completely mineralised by the substitution of silica for the original materials; on the other hand, the bones are much less completely changed, while both bones and teeth are heavy and very dark in colour.

The list of species represented in the collection is short, not more than six or seven, but they appear all to be extinct, though all are referable to living genera, and most of them are nearly allied to existing species. The type of fauna indicated by the list, short as it is, is characteristically South African; in addition to more or less fracmentary remains of fishes, turtles, and a very large crocodile, it includes a hippopotamus, buffalo, two antelopes, a rhinoceros, and an elephant. The species are thus all of hoofed animals, and no representatives of the Carnivora or Rodentia or of other small mammals are included. A strange lack is the absence of the horses, of which not at 
fragment has been detected, though the number of species is so small that no importance can be attached to this fact.

Seeing that these mammals all belong to existing genera, and that, with the exception of the elephant, they differ but comparatively little from Recent Ethiopian species, it is obvious that the fossils cannot have any very great greological antiquity, and probably they should be referred to the later Pliocene. So far, however, as the mammals themselves are concerned, they might almost equally well be regarded as early Pleistocene. Unfortunately they give us little information concerning the origin of the modern South African fauna, or the former relations of the region to other continents.

\section{ARTIODACTYLA.}

\section{HIPPOPOTAMUS.}

Remains of this genus are the most numerous objects in the collection, and of one individual a considerable part of the skeleton is represented. This specimen comprises several thoracic, lumbar, and sacral vertebra, and a number of ribs, the pelvis entire, fragments of several bones of the fore and hind limbs and part of the carpus. All of these agree closely with the corresponding parts of the recent H. amphibius in size and characteristics, and may very well have belonged to that species. A number of isolated teeth, however, indicate a species nearly allied to, but different from the modern one. Unfortunately there is no method at present of determining whether the bones and teeth belong to the same species, and thus it remains uncertain whether the collection contains one species of Hippopotamus or two.

\section{Hippopotamus PONDEROSUs, sp. nov.}

(Plate XVI., Figs. 1-3.)

As the type of this species I have selected an isolated third lower molar of the left side; the other teeth in the collection, which are less characteristic, may or may not have belonged to the same animal. This does not apply to a very much worn first lower molar, which evidently belonged to an older individual.

The third lower molar (M. $\overline{3}$ ) is very large, being but slightly inferior in antero-posterior length to the corresponding tooth of the largest skull of $H$. amphibius, with which I have been able to compare it. and in proportion to that length is somewhat narrower. The tooth was evidently freshly erupted, and shows but slight sign of abrasion. In construction this tooth differs in several respects from that of the modern species, though the differences are not of sufficient importance to require a generic separation. As in $H$. amphibius, the four main cusps of the crown are arranged in two transverse pairs, but the two cusps of each pair are divided from each other by a deeper fissure. 
The posterior, unpaired lobe, or heel, has a more median, less internal position, and is very much higher than is usual in the existing species. In the latter the heel varies very much in development, but I have seen no specimen in which it is so high as in the fossil. Further, in the fossil the heel is separated from the posterior pair of cusps by a much more profound cleft, while the oblique, tuberculated ridge, connecting the heel with the postero-internal cusp, is but feebly indicated, and much less prominent than in $H$. amphibius. As in the modern species, an external cusp is imperfectly separated from the heel, but is much higher and more distinct than in $H$. amphibius. On the posterior face of the heel is a groove, not present in the modern species, which appears like an incipient additional internal cusp. The cingulum is distinctly indicated on the anterior and posterior faces of the crown ; posteriorly it is hardly so thick or prominent as in the existing species, but on the anterior face it is far higher than in the latter, rising for more than half the height of the anterior pair of cusps.

Two isolated lower premolars, contained in the collection, so resemble the type-specimen in appearance, mode of preservation, and degree of abrasion, that they might very well have been derived from the same individual. If so, however, they are relatively somewhat smaller than in the recent species.

The first tooth (P. $\overline{2}$ of the original series) is rather smaller and more slender than in $H$. amphibius, from which it further differs in the presence of a small tubercle on the inner side of the principal cusp (protoconid), and in the much more prominent cingulum, which completely encircles the crown, and is especially strong on the internal, anterior, and posterior faces.

The second premolar $(P . \overline{3})$ differs from that of $H$. amphibius in the more prominent cingulum, in the absence of a posterior basal tubercle, and in the presence of a sort of buttress on each of the outer and inner sides of the principal cusp (protoconid), demarcated by shallow grooves.

In the subjoined table the measurements of the teeth of $H$. amphibius are taken from the unusually large individual mentioned above. All the measurements are in the metric system.

Measurements.

\begin{tabular}{|c|c|c|}
\hline Third lower molar (M. $\overline{3})$, leng & $\begin{array}{l}\text { H. amph. } \\
.0775\end{array}$ & $\begin{array}{c}\text { H. pond. } \\
=076\end{array}$ \\
\hline ansv. diam.) & $\cdot 0425$ & .037 \\
\hline height of heel .. & .037 & $\cdot 048$ \\
\hline t lower premolar $(\mathrm{H}$ & $\circ 35$ & $\circ 3^{2}$ \\
\hline cond lower premolar ( & .046 & $\cdot 037$ \\
\hline
\end{tabular}

The skeletal remains are not sufficiently characteristic for description.

\section{BUBALUS, Frisch.}

The Buffalo is represented by an incomplete right ramus mandibuli, which retains the second and third molars and the alveoli of the other cheek-teeth, but lacking the symphysial region, condyle, coro- 
noid, and angle. Several cervical vertebre, in a more or less fragmentary condition, doubtless are referable to the same species, though probably not to the same individual. The animal is nearly allied to the existing $B$. caffer, but differs sufficiently in tooth-pattern to require its reference to a distinct species.

\section{Bubalus andersoni, sp. nov.}

\section{(Plate XVI., Figs. 4, 4a.)}

The type of this species is the mandible, with second and thircl molars, which is mentioned above. The jaw indicates an animal which is rather larger and more robust than $B$. caffer, judging from the specimens of the latter with which I have had an opportunity to compare it.

The second and third lower molars are somewhat more elongate antero-posteriorly and narrower transversely than in the existing species, and the enamel wall bounding the valleys externally is more simple and less sinuous. The third molar (M. $\overline{3})$ is quite distinctly different from that of $B$. caffer; the enamel loop, or pillar, between the two external crescents, which in the modern species is present in M. $\bar{I}$ and M. $\overline{2}$, but not in M. $\overline{3}$, is very prominently developed, while the fifth lobe, or heel, is much narrower and more compressed laterally, and contains no enamel lake. P'robably in the unworn tooth a valley was present in the heel, but, if so, it must have been shallower than in B. caffer, and disappears at an earlier stage of wear. The heel is connected with the body of the tooth by a much narrower and more constricted neck, the cement-filled valley between the heel and the postero-external crescent being much wider and deeper.

The horizontal ramus of the lower jaw is somewhat shallower dorso ventrally than in the modern species, but is very thick and solid. This species is named in honour of W. Anderson, Esq., Government Geologist of Natal.

Measurements.
Premolar-molar series, length $\ldots \ldots \ldots \ldots \ldots \ldots \ldots$

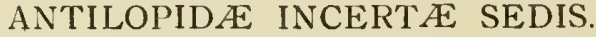

(Plate XVII., Figs. I, 2.)

Two different genera of antelopes are indicated by two different fragmentary specimens. These I have not been able to determine, partly because of the very unsatisfactory condition of the material, and 
partly because the number of recent South African antelopes available for comparison has been limited.

One of the fossils is the posterior portion of the third lower molar of the left side, comprising the posterior pair of crescents and the heel, and belonging to quite a large animal. 'The crown is quite thick and covered with cement, while the enamel, where exposed by the removal of the cement, is seen to be thick, rugose, and much wrinkled on the surface. The talon is very large and of subtriangular shape, flattened on the inner, convex on the outer side. Among recent South African antelopes with which I have had an opportunity to compare this tooth, the closest resemblance is to Connochates, though the fossil is larger and at least specifically different from any of the modern species.

The second specimen is a fragment of the left half of the lower jaw, with the first and second molars in place. The teeth have been so much abraded by water-rolling in sand and gravel that no identification can be made. This is a much smaller animal than the preceding one, and may have been one of the Gazelles, of which Antidorcas is the one most like the fossil. An apparent abnormality is the presence of a deep, cylindrical hole in the enamel of the external crescents of each tooth. In addition M. $I$ is in an evidently diseased condition.

\section{PERISSODACTYLA.}

\section{OPSICEROS, Gloger (ATELODUS, Pomel).}

The African Rhinoceroses are usually referred to the genus (or subgenus) Atelodus of Pomel, but, as Thomas has shown (1895), the latter name is long antedated by the term Opsiceros of Gloger, which should therefore be employed.

In the collection the Rhinoceroses are represented by five loose teeth, all of the upper jaw, and derived from at least two individuals. There is considerable reason to believe that two species, both allied to the recent $O$. bicornis, are represented by these teeth, but it would be premature to recognise more than one until more complete and satisfactory material has been obtained.

\section{Opsiceros SMMPLICIDENS, sp. nov. \\ (Plate XVII., Figs. 3-5.)}

The type of this species is a second upper molar, evidently derived from quite a young anmal, as it is not at all abraded, and is unfortunately incomplete at the base, so that its full transverse width cannot be determined. The tooth is very similar to $\mathrm{M}$. 2 of $\mathrm{O}$. bicornis in a corresponding state of development, but displays a number of differences, which are clearly of specific value.

1. The tooth indicates a larger animal than the average of O. bicornis. 
2. It is more clongate antero-posteriorly, and strikingly narrower and more compressed laterally.

3. In correspondence with this difference in shape the anterior crest (protoloph) is shorter and much more strongly recurved, while the posterior crest (metaloph) is directed more backward, less inward; it mects the outer wall at a very acute angle, and thus makes the posterior valley of a different shape from that of the recent species and much narrower.

4. The outer wall of the crown projects little, if at all, behind the postero-internal cusp (hypocone).

5. The crista is better developed and fuses with the anticrotchet, so as to enclose a small and apparently shallow fossette.

6. The antero-external cusp is larger, and the rib at the junction with the postero-external is much more prominent, while the whole outer surface of the crown is made more undulating by the prominence of this rib and by the presence of a low, broad convexity, somewhat behind the middle of the outer wall.

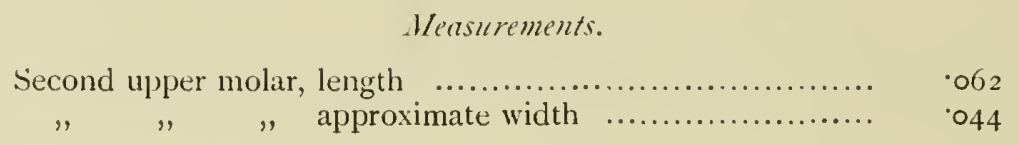

The other teeth, which are provisionally referred to this species, are much abraded, and evidently were derived from an old individual. In part their different appearance is due to this abrasion, but this would not account for the great difference in transverse width. Making all due allowance for the fact that the type specimen is incomplete at the base, it remains true that $M . \underline{2}$ is very narrow and M. 1 is very much broader, much more so than seems likely to occur in one and the same species. However, it would be unwise to establish another species upon the basis of such worn and uncharacteristic teeth as those before us.

The first upper molar has none of the lateral compression which distinguishes the type, but, on the contrary, is subquadrate and very broad, the width exceeding the antero-posterior length. The toothpattern is very simple, the only accessory structure being a low, rounded projection, which arises from the junction of the posterior crest with the outer wall, and thus has a different position from the anticrotchet of $O$. bicomis. The posterior valley has been isolated by wear into an enamel lake, and the cingulum is prominent on the anterior, posterior, and internal faces of the crown. Except for the position of the anticrotchet, this tooth very closely resembles N. $\underline{I}$ of 0 . bicornis in a corresponding stage of wear.

The fourth upper premolar is also much like that of old specimens of the existing species. The tooth is large and subquadrate, though the width decidedly exceeds the antero-posterior length. The external wall is simply convex, and a prominent cingulum surrounds the inner half of the crown; the grinding surface is extremely simple, the only complication being a faintly indicated anticrotchet. In mode- 
rately worn teeth of $O$. bicomis $P .4$ has a double anticrotchet and a minute crista, but in at least some old individuals these features have disappeared, and the tooth is worn to a pattern very similar to the individual before us.

Measurements.

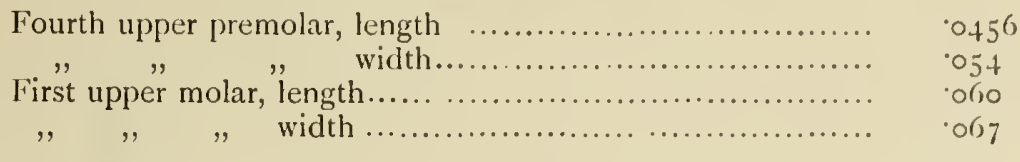

\section{PROBOSCIDEA.}

ELEPHAS (LOXODON), $L$.

The most interesting and significant specimens in the collection are two very well preserved elephant's teeth, which, though not in absolutely the same state of abrasion, are yet probably the right and left third lower molars of the same individual, the difference in the amount of wear being not so great as may often be observed between the two sides of the same jaw.

\section{Elephas (Loxodon) zulu, sp. nov.}

(Plate XVII., Fig. 6; Plate XVIII.)

In view of the notoriously difficult task of determining the species of elephants from isolated teeth, it will serve a useful purpose to introduce the description of these Zululand specimens by a translation of Pohlig's general remarks upon this question.

"General Crown-forms.- These must be regarded as at least as" "important, perhaps in some cases more important, a criterion for the " "systematic division of the Proboscidea as the number of lamelle. "The general distinctions in the crown-forms of the low-crowned "

"E. meridionalis, E. planifrons, from the high-crowned E. indicus," "E. primigenius, and especially E. antiquus, E. namadicus, and" "E. africanus, are well known; the former may be contrasted, as" "Tapinodiscal elephants, with the latter, or Hypselodiscal. . . . Like-" "wise Falconer emphasised the distinction between the narrow and" "broad crowned forms as a specific character; to the former, which" " may be termed Angusticoronate, belong E. africanus, E. antiquus," " and E. namadicus, while to the Laticoronate forms belong the " "Tapinodiscal and the remainder of the Hypselodiscal species." "A further difference consists in the greater or less thickness of the " "enamel plates; as Pachyganal teeth may be instanced the Tapino-" " "discal forms, and, in general, most of the Hypselodiscal species also," "with the exception of the Mammoth, which is especially Endioganal."

"L. Adams has pointed out that the last-mentioned characters" " are not always constant in the same species. . . .

"Fr. Cuvier's separation of E. africanus, as the subgenus" "Loxodon with rhombic lamellar pattern, from E. indicus as the " "typical representative of the genus Elephas sensu stricto, was ex-" 
"tended by Falconer, who referred to Loxodon, besides E. africanus" "(and E. priscus), also $E$. planifrons and $E$. meridionalis, as well as " his 'E.melitensis,' and to Elephas (Enelephas, Falc.) all other forms."

"In his classification Falconer has evidently laid too much stress upon" "the number of lamella, while he did not sufficiently value other" " essential characteristics; thus typical molars of $E$. meridionalis have" " nothing in common with those of E. africamus except the small" "number of lamella, while the former species is far removed from the"

"latter in the form of the crown and in the pattern of the lamellae.

"Estimating all the essential relations of the teeth at their value, we"

"reach the following subgeneric division of the elephants in the" "broader sense :-

"I. Arcumbscodonta. Type: E.meridionalis. Transition" "to the following group formed by $E$. planifrons."

"Tapinodiscal, laticoronate, short and pachyganal "

"molars. Parsilamellate. (Mostly only i 5 lamellæe" "in M. 3.)

"IIa. Loxo-(DISco-)Donta. Type: E. africamus (and E." "priscus). Transition to the following group" "formed by $E$. antiqums. Hypselodiscal, angusti-"

" coronate molars.

"I16. Polmiscononta. Type: E.primigenizs. Transitions" "to the preceding group in $E$. indicus and $E$."

"mamadicus. Hypselodiscal, laticoronate, long," "endioganal molars. Densilamellate. (Mostly" " more than 20 lamella in M. 3.)" (Pohlig, I 888, pp. I $35-138$.

The most obvious object of comparison with $E$. zulu is $E$. africamms, and it will therefore be useful to quote certain of Pohlig's remarks upon the latter species. "Among all normally developed" "elephants E. africanus has relatively the smallest molars and also the" " minimal number of lamella; the maximum, which is rarely attained," "is XI Ix" (xI $3 x$ ? according to Leith Adams). . . . The small size of" "the cheek-teeth, especially in proportion to the gigantic size attained" "by $E$. africames, considerably surpassing that of $E$. indicus, is one of" "the most noteworthy peculiarities of the species. In addition should" "be mentioned the extreme loxolontism, which is approximated by" "E. antiqums only in individual cases, and the narrow form of the" "crowns. . . . The small size, in general, and especially the narrow-" " "ness of the recent elephants' molars, in comparison with those of all " "the fossil species (even E. antiquns included) should be particularly" "noted ; molars of $E$. indicus or $E$. a fricames of more than '086 1m." "width are not known, even in the most gigantic skulls" (Pohlig, I 888, pp. 242-243).

Turning now to the examination of the fossil teeth, one is immediately struck by the fact that they represent a very similar type to those of $E$. (L.) africams, yet differing in such a way as immediately

This means I I fully formed plates with a talon-like, partially formed lamella at each end of the tooth. 
to suggest the more ancient elephants of India and Europe, such as E. planifrons, E. meridionalis, E. antiquus, and E. priscus (Pohlig, non Goldfuss). Indeed, this tooth might almost be described as intermediate in character between Pohlig's two groups, the Archidiscodonta and the Loxodonta. The third lower molar is very large, almost equalling in size that of the most gigantic modern African elephants, and in shape is elongate and rather narrow, though broader relatively than in $E$. africamus, so much so as to verge upon the laticoronate type. It will be observed from the table of measurements that while the breadth of crown equals the maximum recorded, even of the upper molars, for any individual of the existing African or Indian species, the length is considerably less than in these exceptionally gigantic individuals. The degree of abrasion is such that the height of the crown can be only estimated, but, judging from the posterior, unworn portion, this dimension was less than in F. africanus, though probably not sufficiently so to deserve the name Tapinodiscal. This is a distinguishing feature from $E$.planifrons and $E$. meridionalis. The tooth has a strong antero-posterior curvature, with the concavity turned outward and the convexity inward.

In the anterior part of the tooth abrasion has progressed so far as completely to remove all traces of the talon and several laminze, and thus the ridge formula cannot be determined with certainty. It is plain, however, that the number of ridges, not including the talons, cannot have been less than I2, and may have been I 3 . There is some doubt as to the maximum number of lamina which occurs in E. africanus. Adams (1877, p. 35) says: "I can find no record nor" "discover any ultimate molar of $E$. africanus with a larger ridge formula" "than $\mathrm{xI} 3 \mathrm{x}$; indeed, in far the greatest number of specimens it seldom " "exceeds x I Ix." Pohlig, on the other hand, questions this (I 888 , p. 242), and says: "The maximum, which is rarely attained, is x I I x." It thus appears probable that in $E$. zulu the number of ridges was normally greater than in E. africanus, as might be inferred from the narrower shape of the laminæ themselves.

More significant than the number of the ridges is their shape, and one is immediately struck by the fact that in the fossil the pattern is decidedly less loxodont than in the recent African species; the median expansion of each lamina is less, and hence the successive ridges are more widely separated, while in the less abraded ridges the loxodont pattern is not displayed at all, the two enamel walls of each lamina being quite parallel. The enamel is very thick (pachyganal) and very strongly crimped. The lateral terminations of the lamina are either rounded or trifoliate, and each ridge has a feebly curved or crescentic shape, with the horns directed forward. The three posterior ridges have only the points of the digitations exposed, and of these there are four to each ridge, and those of successive plates are arranged in longitudinal rows in a manner suggestive of $E$. meridionalis.

In several respects these teeth of $E$. zulu resemble the curious molars of $E$. antiquus, which were originally described by Falconer as E. priscus: "The discs of wear present an unmistakable resemblance" 
"to those of the existing African elephant, in breadth, lozenge-shaped" "outline and mesial expansion, but when examined in detail, there are" "obvious points of distinction. In the living species the lozenges are" "more distinctly rhomb-shaped; the salient edge of enamel is distinctly" "crimped; the lateral terminations of the rhombs are flattened; and the" " mesial angles of the contiguous discs are either more approximated or" "overlap each other laterally. In E. (Loxodon) priscus the discs are" "rounded at their lateral terminations and broader. Although the "mesial expansion is quite as great as in the African elephant, it is less" "sudden, and in the general outline there is a tendency to a reniform or " "obsolete crescentic shape, the anterior enamel boundary of each disc" "being concave and the posterior convex" (1868, vol. ii., p. 97, pl. viii., figs. 3,4$)$.

In $E$. zulu the lozenge pattern is less distinct than in these exceptional teeth of $E$. antiquns, and the enamel is even more crimped and thicker than in E. africanus, but there is a strong resemblance to both species.

Measurements.

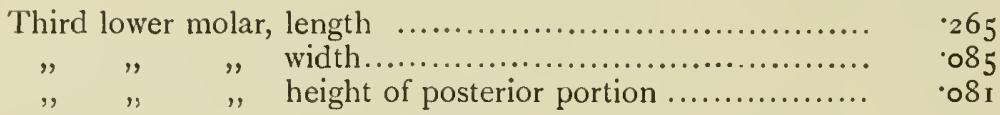

From a single pair of teeth it would be a hazardous undertaking to determine the phylogenetic significance of $E$. zulu, yet, so far as the evidence reaches, it gives us no reason to suppose that this species was not the direct ancestor of $E$. africanus. In most discussions concerning the descent of the various species of elephants it is usually taken for granted that evolutionary progress in molar structure has always been by the addition of plates or discs. In many, perhaps most, cases this is probably true, but it is not necessarily true of all. The example of certain phyla, such as the Rodents, shows us that, within the limits of a single family, dental evolution may proceed, now by increased complication and number of elements, now by simplification and reduction of elements already present.

Should E. zulu eventually prove to be the actual ancestor of E. africanus, it would tend to give the latter a less isolated position, connecting it with Asiatic and European species. At all events, it is extremely interesting and important to find in South Africa an elephant with so many points of resemblance to species characteristic of the northern hemisphere.

\section{PAPERS QUOTED.}

Adams, A. Leith, 1877.--Monograph of British Fossil Elephants. Palæontographical Society, London, $1877-188 \mathrm{r}$.

Falconer, H., I868.-Palæontological Memoirs. London, I 868.

Pohlig, H., I 888.- Dentition und Kranologie des Elephas antiquus Falc., \&c. Nova Acta der Ksl. Leop.-Carol. Deutschen Akademie der Naturforscher., bd. liii., No. I.

Thomas, O., 1895.-An Analysis of the Mammalian Generic Names in Dr. C. IV. L Gloger's Naturgeschichte. Ann. and Mag. Nat. Hist. 6th ser., vol. xv., p. I89. 


\section{PLATE XVI.}

FIG. I.-Hippopotamus pondevosus, sp. nov. Right $3^{\text {rd }}$ lower molar, outer side, nat. size.

IA.- Hippopotanus ponderosus, sp. nov. The same tooth, crown-view.

2.- Hippopotanus pondevosus. Right ist lower premolar, outer side, nat. size.

3.-Hippopotamus ponderosus. Right 2nd lower premolar, outer side, nat. size.

4.-Bubalus andersoni, sp. nov. Right lower jaw, external side; $\frac{4}{9}$ nat. size.

4A.-Bubalus andersoni, sp. nov. The same, crown-view; about $\frac{2}{3}$ nat. size. 

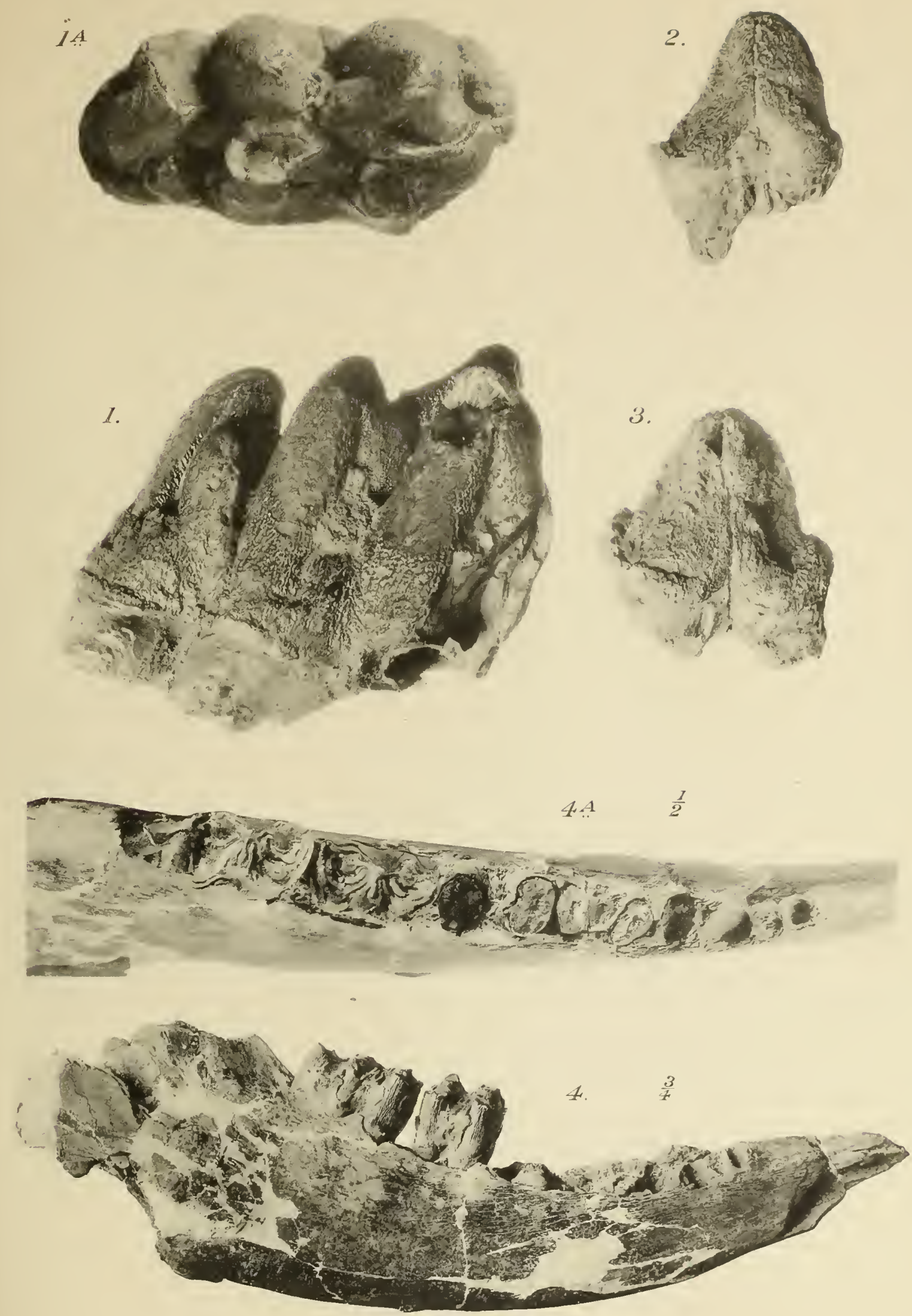




\section{PLATE XVII.}

FIG. I.-Undetersnined Antelope. Fragment of left ramus mandibuli, with ist and 2nd molars, nat. size.

2.- Undetermined Antelope. Posterior half of left 3 rd lower molar, crown-view, nat. size.

3.-Opsiceros simplicidens, sp. nov. Left and upper molar (type specimen) of young individual, unworn, crown-view, nat. size.

4.- Opsiceros simplicidens,? Right rst upper molar of old animal, crown-view, nat. size.

5.-Opsiceros simplicidens, ? Left $4^{\text {th }}$ upper premolar, presumably of same individual as fig. 4 , crown-view, nat. size.

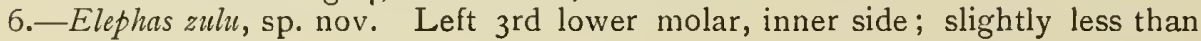
$\frac{1}{3}$ nat. size. 


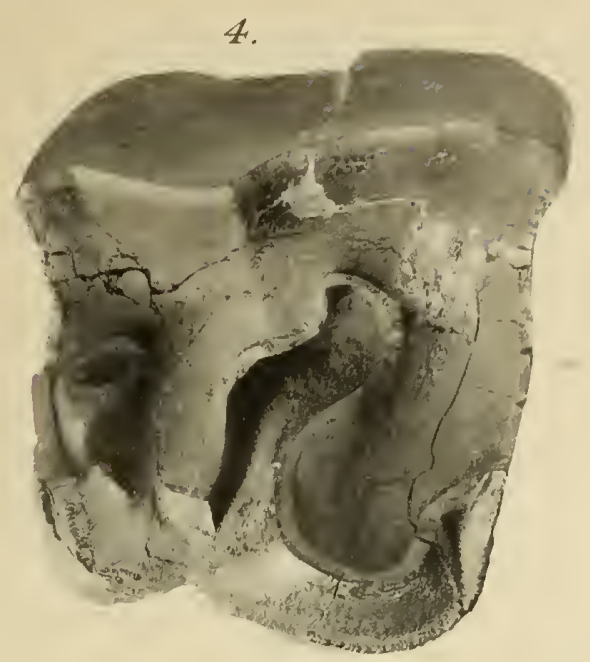

5.

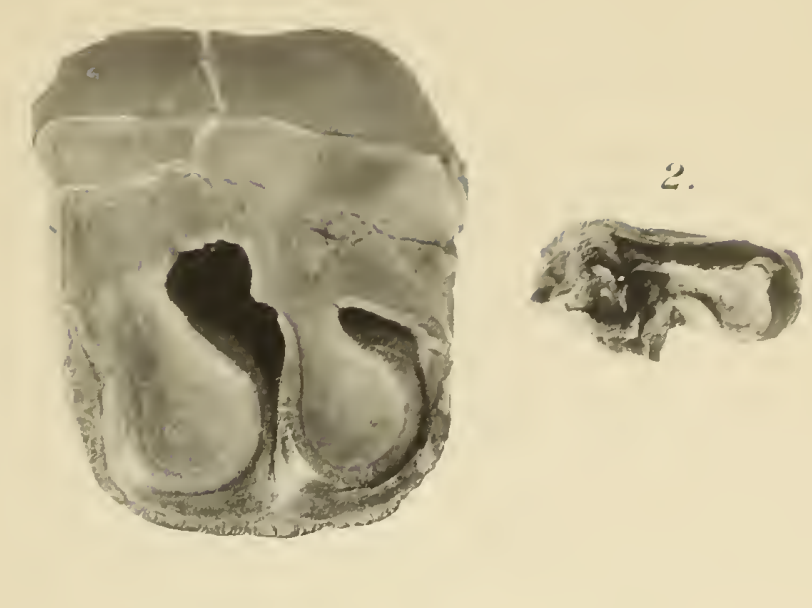

3.
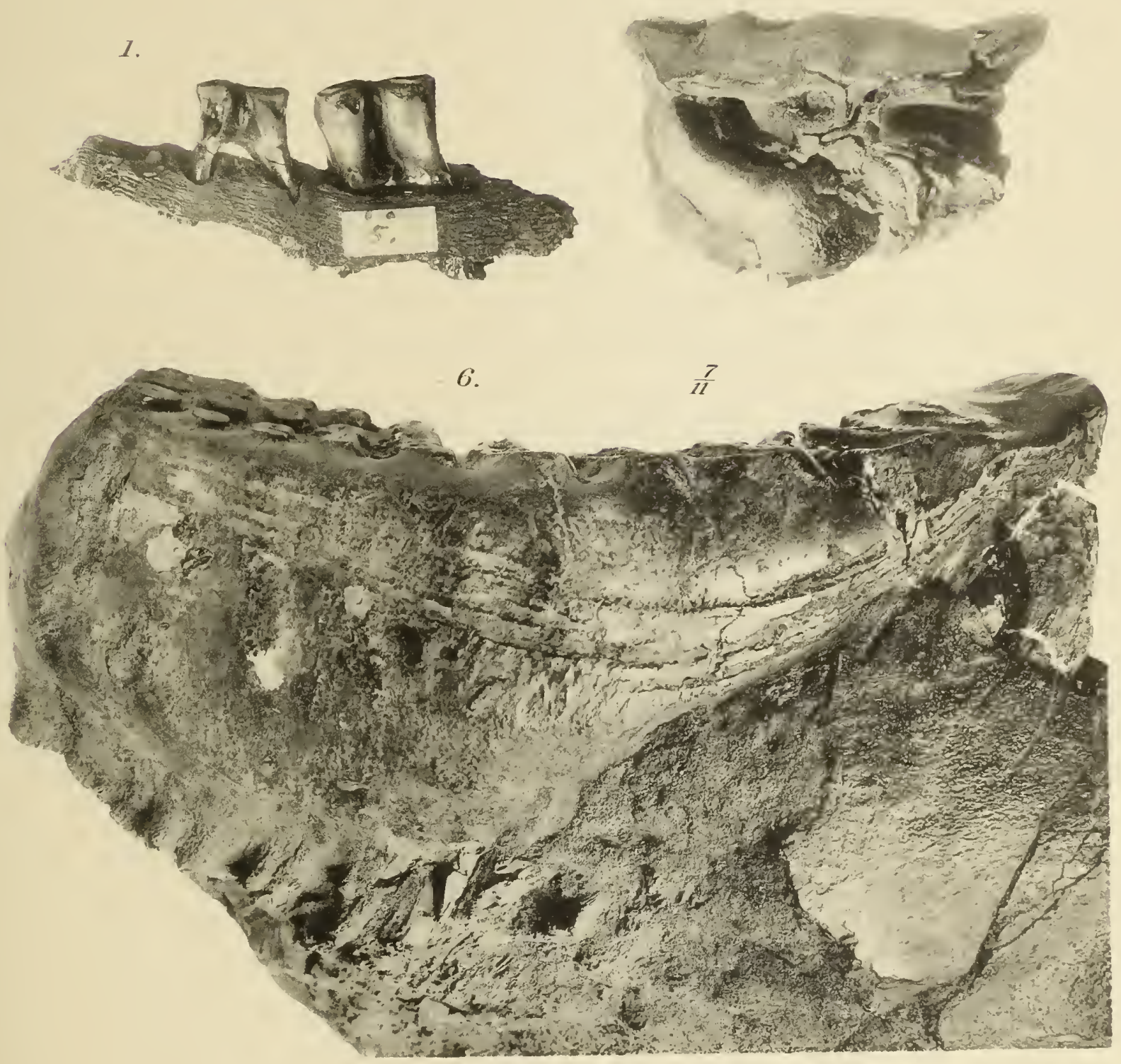



\section{PLATE XVIII.}

Fig. I.-Elephas zulu, sp. nov. Left 3 rd lower molar, crown-view; slightly less than $\frac{3}{5}$ nat. size. Same tooth as Plate XVII., fig. 6.

2.-Elephas zulu, sp. nov. Right 3 rd lower molar, crown-view; approxinately $\frac{5}{7}$ nat. size. The anterior end of this tooth is broken away.

2A.-Elephas zulu, sp. nov. The same tooth from the inner side. 

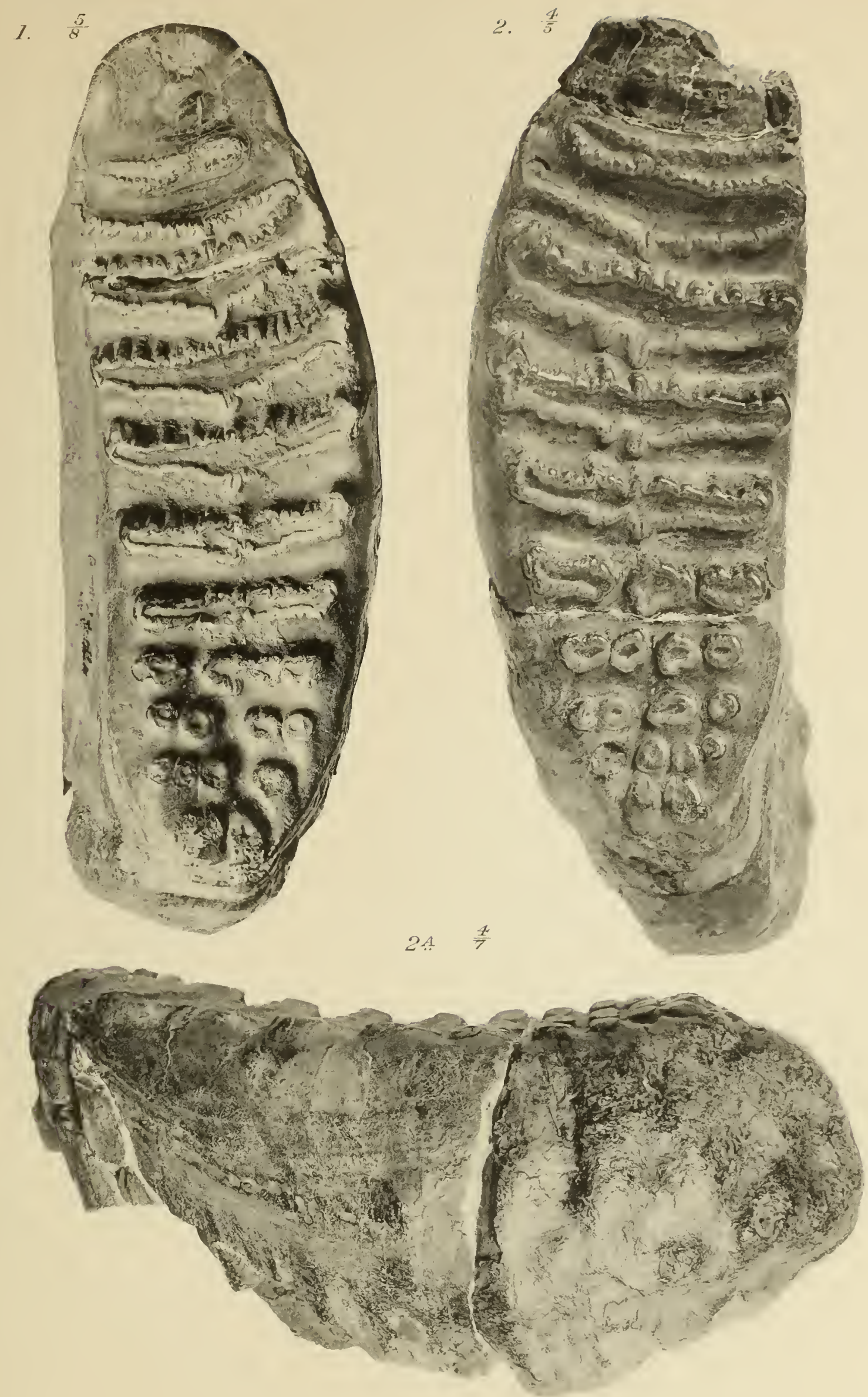




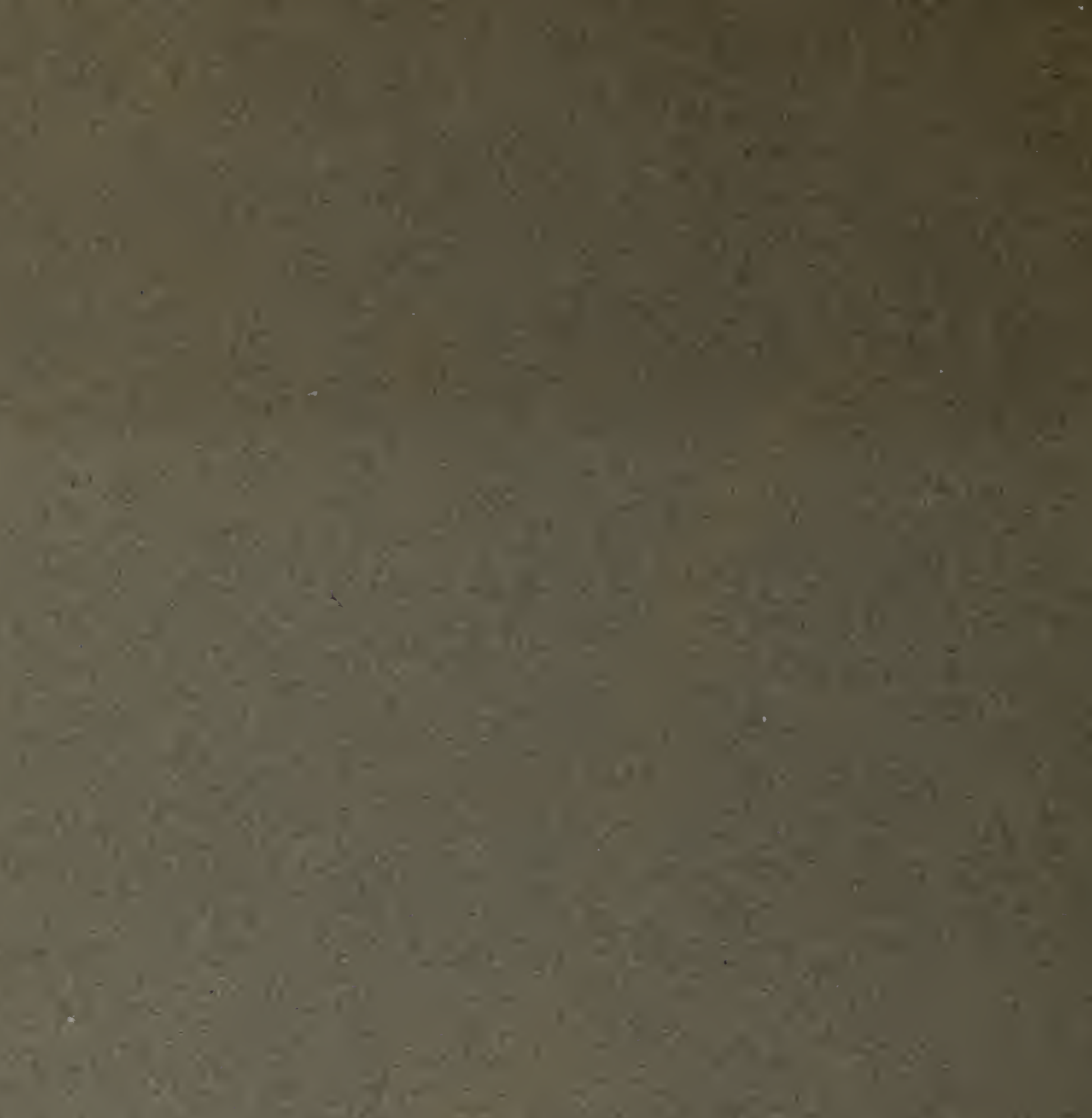

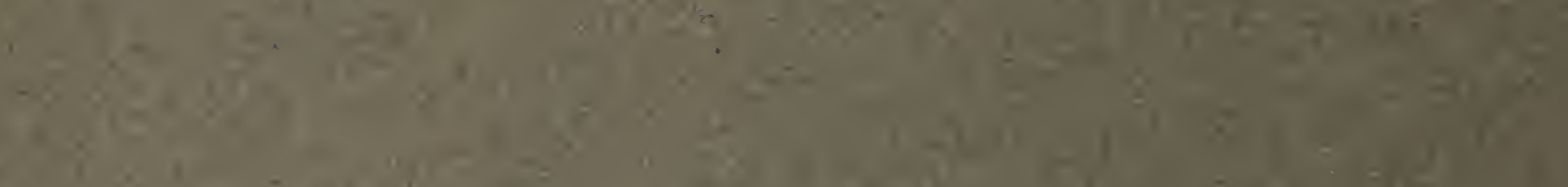

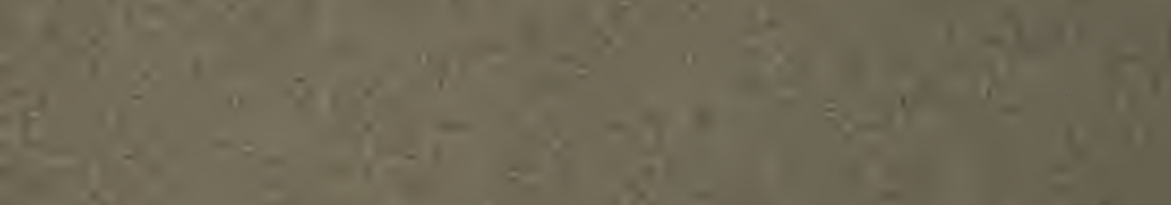

